\title{
CARACTERIZAÇÃO MORFOLÓGICA E MOLECULAR DE GENÓTIPOS DE MANGABA ${ }^{1}$
}

\author{
SIMONE ALVES SILVA², ELIZANGELA MÉRCIA DE OLIVEIRA CRUZ ${ }^{3}$, \\ RONALDO VIANA DOS REIS ${ }^{2}$, CLAUDIA FORTES FERREIRA ${ }^{4}$, \\ ADRIANA RODRIGUES PASSOS
}

RESUMO- O objetivo do trabalho foi verificar a divergência genética entre 25 genótipos de mangaba da região de Iramaia-Chapada Diamantina-Bahia, utilizando os marcadores morfológicos e os marcadores RAPD. As seguintes aferições foram realizadas nos frutos maduros: diâmetro longitudinal (DL) e transversal (DT), massas do fruto (MF), da semente (MS) e da polpa (MP), rendimento de polpa (\%P) e a contagem do número de sementes (NS). Os caracteres químicos avaliados no fruto maduro foram: $\mathrm{pH}$, acidez (Ac), sólidos solúveis totais (SST), ácido ascórbico (AA), açúcar total (ACT) açúcar redutor (ACR), açúcar não redutor (ACNR) e relação sólidos solúveis totais: acidez (SST/Ac). Para a amplificação, foram testados 51 random primers. Os resultados médios das aferições foram: DL (37,03 mm), DT (34,34 mm), MF (24,45 g), MS $(2,42 \mathrm{~g})$, MP $(22,03 \mathrm{~g})$, e NS $(11,14)$. Para as avaliações químicas, foram verificados os resultados médios:

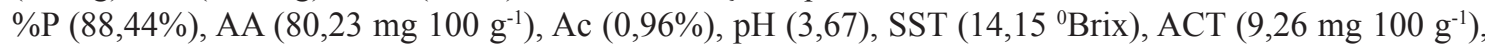
ACR (5,13 mg $\left.100 \mathrm{~g} \mathrm{~g}^{-1}\right)$, ACNR (4,13 mg $\left.100 \mathrm{~g}^{-1}\right)$ e SST/Ac (14,56 mg 100 g $\left.{ }^{-1}\right)$. Oito random primers foram selecionados por apresentarem bandas mais intensas, e seis (OPA 08, OPB 12, OPB 19, OPH 15, OPH 18 e OPH 19) geraram 28 regiões de bandas polimórficas. Dentre os marcadores morfológicos, MF e MP foram os que mais efetivamente contribuíram para a divergência genética. A formação de seis e sete grupos para os marcadores moleculares e morfológicos, respectivamente, indicou a presença de variabilidade genética na população avaliada.

Termos para indexação: Hancornia speciosa Gomes, RAPD, divergência genética.

\section{MORPHOLOGICAL AND MOLECULAR CHARACTERIZATION OF MANGABA GENOTYPES}

\begin{abstract}
The objective was to assess the genetic diversity among 25 Mangaba genotypes in the Iramaia-Chapada Diamantina region, Bahia, using morphological markers and RAPD markers. The following measurements were performed in mature fruits: longitudinal (LD) and transverse (TD) diameter, fruit $(\mathrm{FM})$, seed (SM) and the pulp (PM) mass, pulp yield (\% P) and the count seed number (SN). The chemical characters were evaluated in mature fruit: $\mathrm{pH}$, acidity (Ac), total soluble solids (TSS), ascorbic acid (AA), total sugar (TS) reducing sugar (RS), non-reducing sugar (NRS) and total soluble solids /acidity (TSS/Ac). For amplification were tested 51 random primers. The average results of the measurements were LD (37.03 $\mathrm{mm}$ ), TD (34.34 mm), FM (24.45 g), SM (2.42 g), PM (22.03 g), and SN (11.14). For chemical evaluations

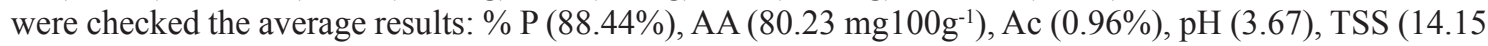

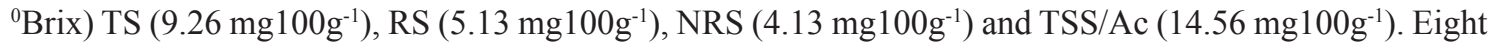
random primers were selected for having more intense bands and six (OPA 08, OPB 12, OPB 19, OPH 15, OPH 18, OPH 19) were sufficient to generate 28 polymorphic bands. Among the morphological markers, FM and PM were the most effectively contributed to divergence. The formation of six and seven groups for molecular markers and morphological, respectively, indicated the presence of genetic variability in the population. .
\end{abstract}

Index terms: Hancornia speciosa Gomes, RAPD, genetic diversity.

\footnotetext{
'(Trabalho 161-13). Recebido em: 05-04-2013. Aceito para publicação em: 07-10-2013.

${ }^{2}$ Universidade Federal do Recôncavo da Bahia/CCAAB/NBIO. Campus Universitário. Cruz das Almas-Ba. Cep: 44.380.000. E-mails: simonealves22@gmail.com, ronasviana@yahoo.com.br

${ }^{3}$ Universidade Federal do Sergipe. Rede Nordeste de Biotecnologia. E-mail: elizangelacruz@hotmail.com

${ }^{4}$ Embrapa Mandioca e Fruticultura. Rua Embrapa s/n Cruz das Almas-Ba. Cep: 44380-000. E-mail: claudiaf@cnpmf.embrapa.br ${ }^{5}$ Universidade Estadual de Feira de Santana (UEFS). Unidade Experimental Horto Florestal Av. Pres. Dutra, Santa Mônica, s/n. Cep: 44.055-000. Feira de Santana-Ba. E-mail: adrianarpassos@yahoo.com.br
} 


\section{INTRODUÇÃO}

Hancornia speciosa Gomes, popularmente conhecida como mangabeira, é uma frutífera nativa do Brasil, ocorrendo espontaneamente nas regiões sudeste, norte, nordeste e centro-oeste. A mangabeira vem destacando-se por seus frutos serem consumidos maduros, in natura e industrializados. Não obstante sua importância, os caracteres que devem ser considerados no melhoramento genético ainda não estão bem definidos para a mangabeira, pois ela não passou pelo processo de domesticação (GANGA et al., 2010).

A utilização de técnicas precisas para a identificação e a caracterização de genótipos é essencial para programas de melhoramento e para a proteção de cultivares. Os marcadores morfológicos ainda são muito utilizados, entretanto podem apresentar problemas de baixa eficiência no diagnóstico de avaliação da variabilidade disponível. Por outro lado, marcadores moleculares são altamente precisos por detectarem diferenças em nível de DNA e por exibirem suficiente polimorfismo para discriminar os genótipos (SAMAL et al., 2011).

Estudos sobre a caracterização morfológica de mangaba, apesar de incipientes, são encontrados na literatura (SOUZA et al., 2007; SANTOS et al., 2009). Entretanto, no que tange aos marcadores moleculares, o cenário é mais crítico; sendo raros os trabalhos utilizando marcadores moleculares para a caracterização da mangabeira e de seus frutos (GANGA et al., 2010).

Os marcadores moleculares são importantes ferramentas para a detecção da variabilidade com precisão, uma vez que, com o advento das técnicas modernas de biologia molecular, surgiram diversos métodos de detecção de polimorfismo em nível de DNA, tendo como maior interesse a perspectiva de estabelecer ligações entre os marcadores e os genes que controlam determinada característica (OLIVEIRA et al., 1996).

Dentre essas aplicações, destaca-se o estudo da diversidade genética em programas de melhoramento, especialmente na elucidação da variabilidade genética disponível para os melhoristas. Os marcadores moleculares têm sido utilizados em estudos de diversidade, em muitas espécies vegetais (JOSHI et al., 2000; GAUDEUL et al., 2000; QIAN et al., 2001; GUASMI et al., 2008).

Os marcadores RAPD (Random Amplified Polymorphic DNA) vêm sendo utilizados para estudos da variabilidade e/ou divergência genética também em frutífera, a exemplo de Musa spp. e Mangifera indica L (BROWN et al., 2009; SAMAL et al., 2011); Psidum spp. (GOMES FILHO et al. 2010) Hancornia speciosa Gomes (DA SILVA et al., 2011).

Neste contexto, objetivou-se, neste trabalho, investigar a diversidade genética entre genótipos de mangaba, da região de Iramaia - Chapada Diamantina - BA, por meio dos marcadores morfoagronômicos e RAPD.

\section{MATERIAL E MÉTODOS}

\section{Material Vegetal}

Para realizar o experimento, vinte e cinco genótipos de mangaba $\left(\mathrm{IR}_{1}, \mathrm{IR}_{2}, \mathrm{IR}_{3}, \mathrm{IR}_{4}, \mathrm{IR}_{5} \mathrm{IR}_{6}, \mathrm{IR}_{7}\right.$, $\mathrm{IR}_{8}, \mathrm{IR}_{9}, \mathrm{IR}_{10}, \mathrm{IR}_{11}, \mathrm{IR}_{12}, \mathrm{IR}_{13}, \mathrm{IR}_{14}, \mathrm{IR}_{15}, \mathrm{IR}_{16}, \mathrm{IR}_{17}$, $\mathrm{IR}_{18}, \mathrm{IR}_{19}, \mathrm{IR}_{20}, \mathrm{IR}_{21}, \mathrm{IR}_{22}, \mathrm{IR}_{23}, \mathrm{IR}_{24}$ e IR $\mathrm{IR}_{25}$ ) foram coletados no campo, em diferentes locais da região Iramaia-BA. O clima é do tipo semiárido, subúmido a seco, vegetação tipo caatinga densa com palmeiras, sendo a latitude de $13^{\circ} 18^{\prime} 00$ e longitude de $40^{\circ} 58^{\prime} 00$.

Foram coletados folhas jovens e frutos em diferentes estádios de maturação, acomodados em caixotes plásticos e transportados para o Laboratório de Tecnologia de Alimentos do Departamento de Química Agrícola e Solos, da Escola de Agronomia da Universidade Federal do Recôncavo da Bahia UFRB, no município de Cruz das Almas - BA.

No laboratório, foram selecionados 30 frutos maduros por genótipo para a realização das análises, descartando-se aqueles com danos e uniformizandoos quanto ao estádio de maturação (prontos para o consumo), indicada pela presença da coloração amarelada ou avermelhada. Por gravimetria, utilizando balança analítica digital, foram obtidas as massas da semente (MS), da polpa (MP) e do fruto (MF). O número de sementes por fruto (NS) foi obtido por contagem e também foram avaliados os diâmetros longitudinal (DL) e transversal (DT) do fruto com auxílio de paquímetro.

\section{Caracteres físico-químicos}

Foram avaliados nos frutos maduros: $\mathrm{pH}$ da polpa, acidez (Ac), sólidos solúveis totais (SST), ácido ascórbico (AA), açúcares totais (ACT), açúcares redutor (ACR) e não redutor (ACNR), utilizando os métodos-padrão, segundo Instituto Adolfo Lutz (2008).

Os dados foram analisados por estatística descritiva, utilizando-se de medidas de tendência central (média) e de variabilidade dos dados (desvio-padrão e coeficiente de variação). Foram realizadas análises multivariadas por meio de 
análise de agrupamento e análise de componentes principais. Como medida de dissimilaridade, foi utilizada a distância euclidiana média, e com base nos cálculos foram estabelecidos gráficos de dispersão e dendrogramas, os quais permitiram agrupar os genótipos e classificar os mais divergentes. As análises foram realizadas através do Aplicativo Computacional Genes (CRUZ, 2006).

\section{Caracterização do DNA genômico}

Folhas jovens foram coletadas dos genótipos em estudo, acondicionadas em papel- alumínio e colocadas em caixa de isopor contendo gelo seco em seu interior. A seguir, foram transportadas para o laboratório de Biotecnologia Molecular da Embrapa Mandioca e Fruticultura, no município de Cruz das Almas-Ba, armazenadas a $-80^{\circ} \mathrm{C}$ até o início das avaliações.

O DNA foi extraído segundo o protocolo de Doyle e Doyle (1990), e as amplificações, efetuadas no termociclador (MJ Research, Inc modelo PTC 100). A reação de amplificação constituiu-se de 2,0 mL de DNA genômico [5 ng], 1,5 mL de tampão de PCR 1X, 0,45 mL de $\mathrm{MgCl}_{2} 50 \mathrm{mM}, 0,60 \mathrm{~mL}$ de dNTPs 2,5 mM, 0,50 $\mathrm{mL}$ de Taq DNA polimerase, 3,0 $\mathrm{mL}$ de Primer R/F (4mM) e 6,95 mL de água Milli-Q,

$\mathrm{O}$ programa utilizado para as amplificações seguiu de um ciclo de $94^{\circ} \mathrm{C} / 1$ minuto, $32^{\circ} \mathrm{C} / 1$ minuto, $72^{\circ} \mathrm{C} / 1$ minuto; 39 ciclos de $94^{\circ} \mathrm{C} / 15$ segundos, $32^{\circ} \mathrm{C} / 30$ segundos, $72^{\circ} \mathrm{C} / 1$ minuto; um ciclo de $72^{\circ} \mathrm{C} / 7$ minutos.

Foram testados 51 random primers da marca "Operon", com os produtos das reações de amplificações separados em gel de agarose $(1,2 \%)$ corados com brometo de etídio e fotografados com luz ultravioleta, utilizando o sistema Kodac Digital. Os dados obtidos foram registrados na forma de presença (1) e ausência (0) de bandas. As distâncias entre os genótipos foram calculadas com base no coeficiente de similaridade de Nei e Li (1979). De acordo com as distâncias genéticas, foi elaborada análise de agrupamento pelo método da variância mínima, utilizando o programa estatístico Tools for population genetic analysis - TFPGA (MILLER,1997).

\section{RESULTADOS E DISCUSSÃO}

Considerando as avaliações físicas e químicas (Tabela 1), os genótipos $\mathrm{IR}_{3} \mathrm{IR}_{6} \mathrm{IR}_{16} \mathrm{IR}_{20}$, e $\mathrm{IR}_{25}$ apresentaram os valores de DL, DT, MF, MS e NS acima da média. O genótipo $\mathrm{IR}_{2}$ também se destacou nesses caracteres físicos, à exceção da MS $(2,13)$.
Guilherme et al. (2007) constataram os valores médios de $37,59 \pm 10,66 \mathrm{~mm}$ e $34,53 \pm 8,83 \mathrm{~mm}$ para o diâmetro longitudinal e diâmetro equatorial, respectivamente, para os frutos da mangabeira oriundos do norte de Minas Gerais.

Para as avaliações químicas (Tabela 1), os genótipos $\mathrm{IR}_{02}$ e $\mathrm{IR}_{16}$ foram os que apresentaram os maiores valores para a maioria das características físico-químicas estudadas. Foi verificado que os valores encontrados neste trabalho estão de acordo com Souza et al., (2007) e Santos et al. (2009). Os valores verificados para SST nos genótipos $\operatorname{IR}_{14}(17$ ${ }^{0}$ Brix $), \operatorname{IR}_{13}\left(16,7^{\circ}\right.$ Brix $), \operatorname{IR}_{16}\left(16,6^{\circ}\right.$ Brix $)$ e $\operatorname{IR}_{02}(16,4$ $\left.{ }^{0} \mathrm{Brix}\right)$ estão acima dos valores médios encontrados em estudos com outras fruteiras, como manga e bacuri (SILVA et al., 2010; BEZERRA et al., 2011).

De acordo com Ferreira et. al. (2007), os frutos da mangabeira são aromáticos, delicados, saborosos e nutritivos, com teores de vitaminas e sais minerais superiores aos da maioria das espécies frutíferas. Essas características demonstram o potencial que a mangabeira tem para ser explorada em programas de melhoramento e no mercado de fruteiras no cenário nacional.

Com os valores dos componentes principais, as estimativas dos autovalores e os coeficientes de ponderação associados a cada caráter (Tabela 2), foi possível verificar um acúmulo de $83,27 \%$ da variância total nos dois primeiros componentes principais. Os atributos MF e MP foram os de maior importância para discriminarem os genótipos estudados, considerando as estimativas dos autovalores com contribuição relativa de $37,76 \mathrm{~g}$ e $29,29 \mathrm{~g}$, respectivamente.

O resultado desta análise deve ser considerado com cautela, uma vez que não foram feitos testes para avaliar a correlação e a colinearidade entre as características.

O agrupamento de genótipos de mangabeira estabelecidos com base na distância euclidiana média (Figura 1) demonstra a formação de sete grupos, significando que muitos cruzamentos divergentes podem ser efetuados entre os genótipos avaliados. A maior distância observada foi entre $\operatorname{IR}_{7}$ e $\operatorname{IR}_{11}(0,079)$.

De acordo com o dendrograma obtido a partir de dados moleculares, foi verificada a formação de seis grupos distintos, confirmando a variabilidade encontrada através dos marcadores morfológicos (Figura 2). A maior distância observada ficou entre $\mathrm{IR}_{2}$ e $\operatorname{IR}_{21}(0,41)$, enquanto a menor distância foi verificada entre os genótipos $\operatorname{IR}_{21}$ e $\operatorname{IR}_{23}(0,0)$. Não foi obtido um dendograma dos descritores morfológicos semelhante ao produzido pela técnica de RAPD. Altas correlações nem sempre são obtidas, devido à 
interação genótipo X ambiente, que afeta a expressão do genótipo (SAMAL et al., 2011).

Dentre os 51 random primers utilizados neste trabalho, oito permitiram bandas visíveis com eficiência na amplificação, e os demais não apresentaram poliformismo. Dos oito random primers amplificados, dois foram monomórficos (OPA 09 e OPAC 04) e seis (OPA 08, OPB 12, OPB 19, OPH 15, OPH 18 e OPH 19) foram polimórficos, gerando 19 bandas polimórficas (Tabela 3 ). O random primer que apresentou maior polimorfismo foi $\mathrm{OPH}$ 19 , com os fragmentos amplificados entre $400 \mathrm{e}$ $1.500 \mathrm{pb}$. Da Silva et al.(2011), trabalhando com divergência genética entre acessos de mangabeira, utilizaram 12 random primers, os quais permitiram a obtenção de 106 bandas, sendo 92 delas polimórficas $(86,79 \%)$.

Mais testes ou outros marcadores podem ser avaliados para se buscar uma análise mais refinada da variabilidade genética da mangabeira; entretanto, como são incipientes os trabalhos referentes às características moleculares da mangaba, os resultados aqui obtidos, mesmo com o número pequeno de marcas polimórficas, colaboram para o programa de melhoramento da espécie.

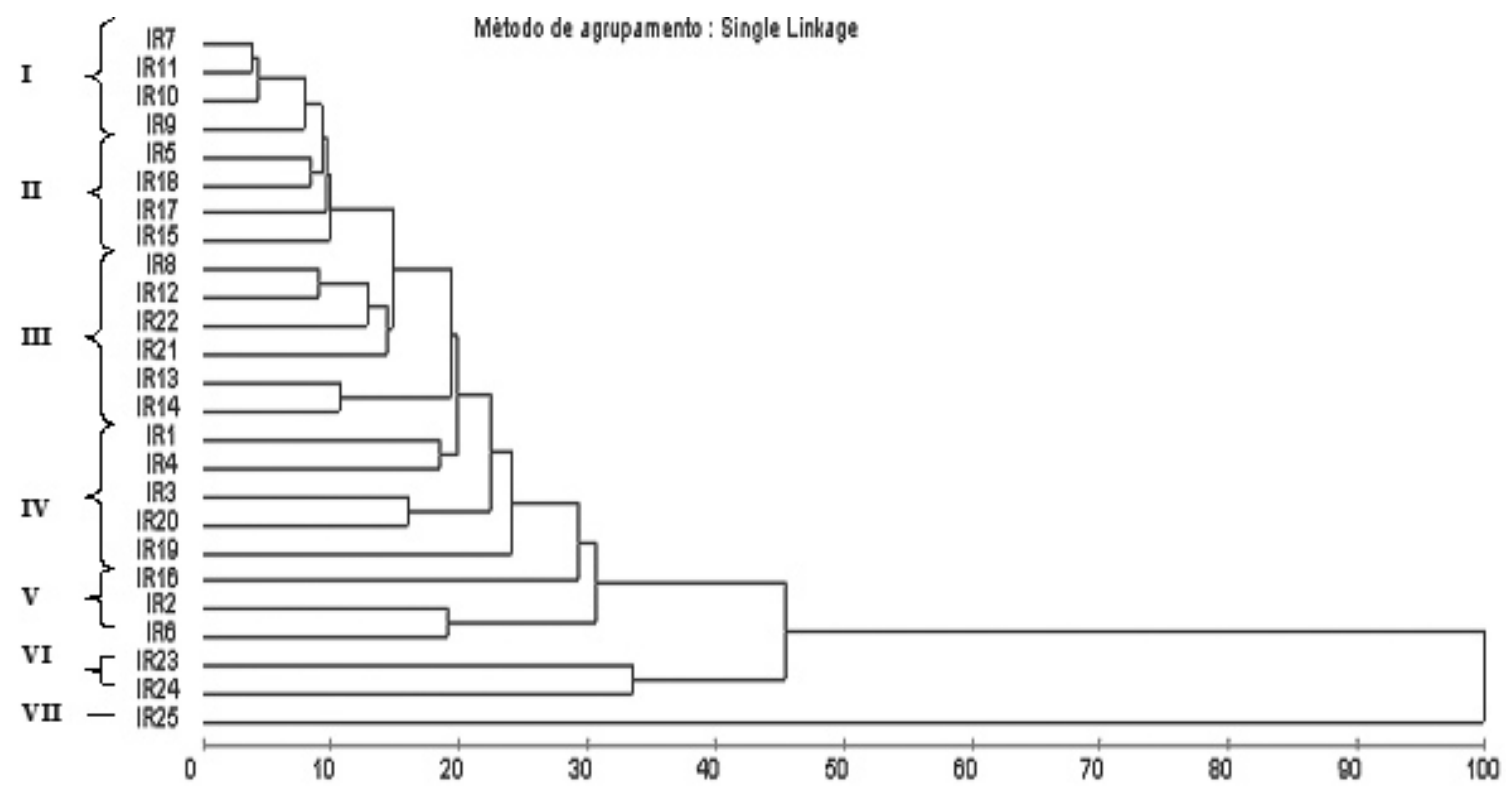

FIGURA 1- Dendrograma construído com 25 genótipos de mangabeira usando características morfoagronômicas dos frutos e a distribuição dos grupos estabelecidos com base na distância Euclidiana Média. 


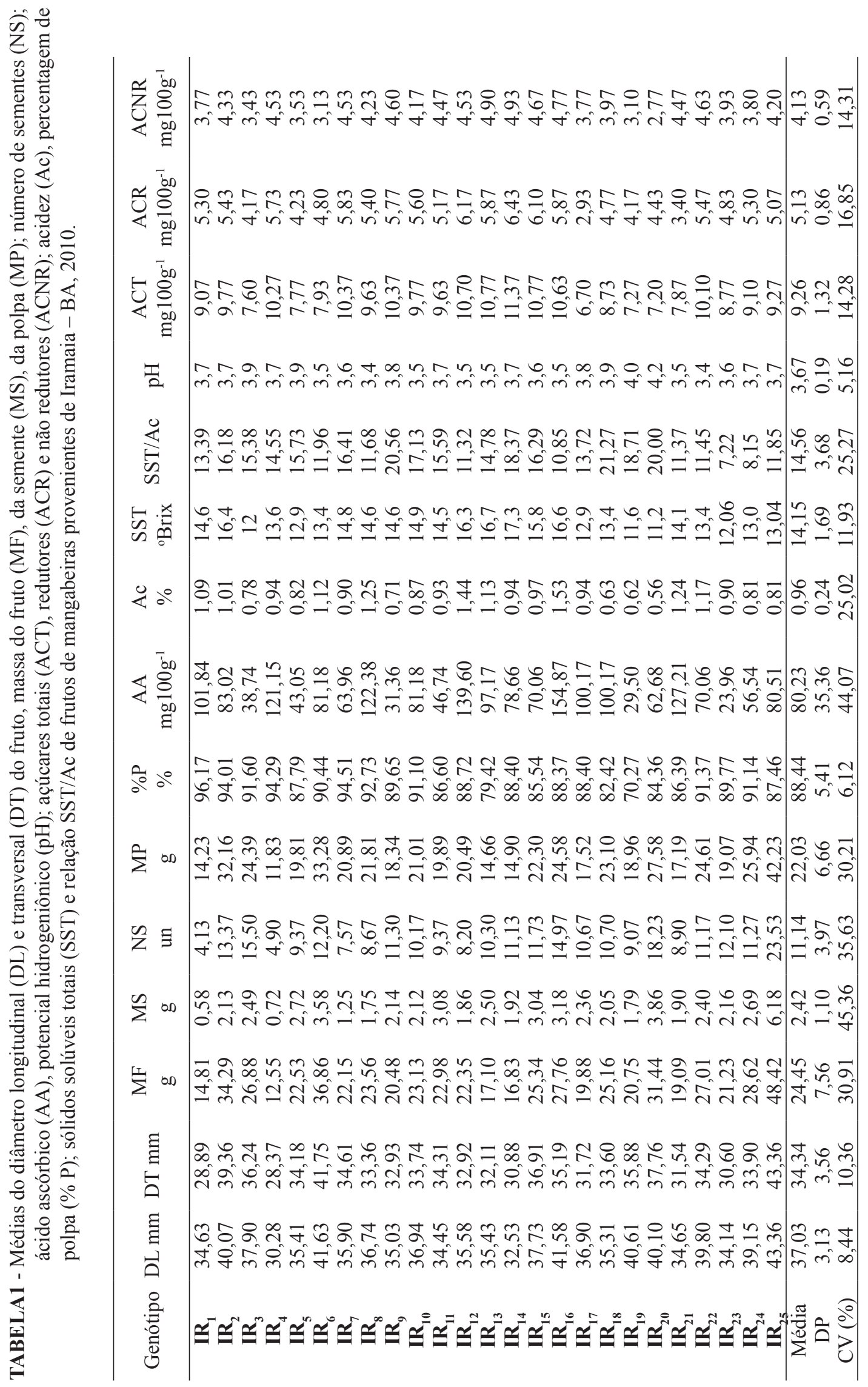


TABELA 2 - Estimativas dos autovalores e contribuição relativa dos caracteres dos frutos de mangabeira provenientes da região de Iramaia-BA, 2010.

\begin{tabular}{ccccc}
\hline & \multicolumn{2}{c}{ Estimativa de autovalores } & & \\
\cline { 2 - 4 } Componentes principais & Variância (\%) & \% Acumulada & Caracteres & Contribuição Relativa \\
\hline$Y_{1}$ & 58,77 & 58,77 & MF & 37,76 \\
$\mathrm{Y}_{2}$ & 24,50 & 83,28 & $\mathrm{MP}$ & 29,29 \\
$\mathrm{Y}_{3}$ & 9,038 & 92,32 & $\mathrm{NS}$ & 10,41 \\
$\mathrm{Y}_{4}$ & 3,71 & 96,04 & $\mathrm{DTF}$ & 8,36 \\
$\mathrm{Y}_{5}$ & 2,51 & 98,56 & $\mathrm{DLF}$ & 6,46 \\
$\mathrm{Y}_{6}$ & 0,93 & 99,49 & $\mathrm{SST}$ & 5,18 \\
$\mathrm{Y}_{7}$ & 0,48 & 99,97 & $\mathrm{ACT}$ & 2,46 \\
$\mathrm{Y}_{8}$ & 0,022 & 100,0 & AC & 0,77 \\
\hline
\end{tabular}

MF: Massa do fruto; MP: massa da polpa; NS: número da semente; DFT: diâmetro transversal do fruto; DLF: diâmetro longitudinal do fruto; SST: sólidos solúveis totais; ACT: açúcares totais; AC: acidez.

TABELA 3 - Primers utilizados, sequência 5'-3', bandas monomórficas, bandas polimórficas e total de bandas geradas por marcadores RAPD em genótipos de mangabeira.

\begin{tabular}{ccccc}
\hline Primer & Sequência (5'-3') & Bandas polimórficas & Bandas monomórficas & Total \\
\hline OPA 08 & GTGAGCTAGG & 2 & 2 & 4 \\
OPB 12 & CCTTGACGCA & 1 & 2 & 3 \\
OPB 19 & ACCCGGGAAG & 3 & 0 & 3 \\
OPH 15 & AATGGCGCAG & 4 & 3 & 7 \\
OPH 18 & GAATCGGCCA & 4 & 1 & 5 \\
OPH 19 & CTGACCAGCC & 5 & 1 & 6 \\
\hline Total & & 19 & 9 & 28 \\
\hline
\end{tabular}

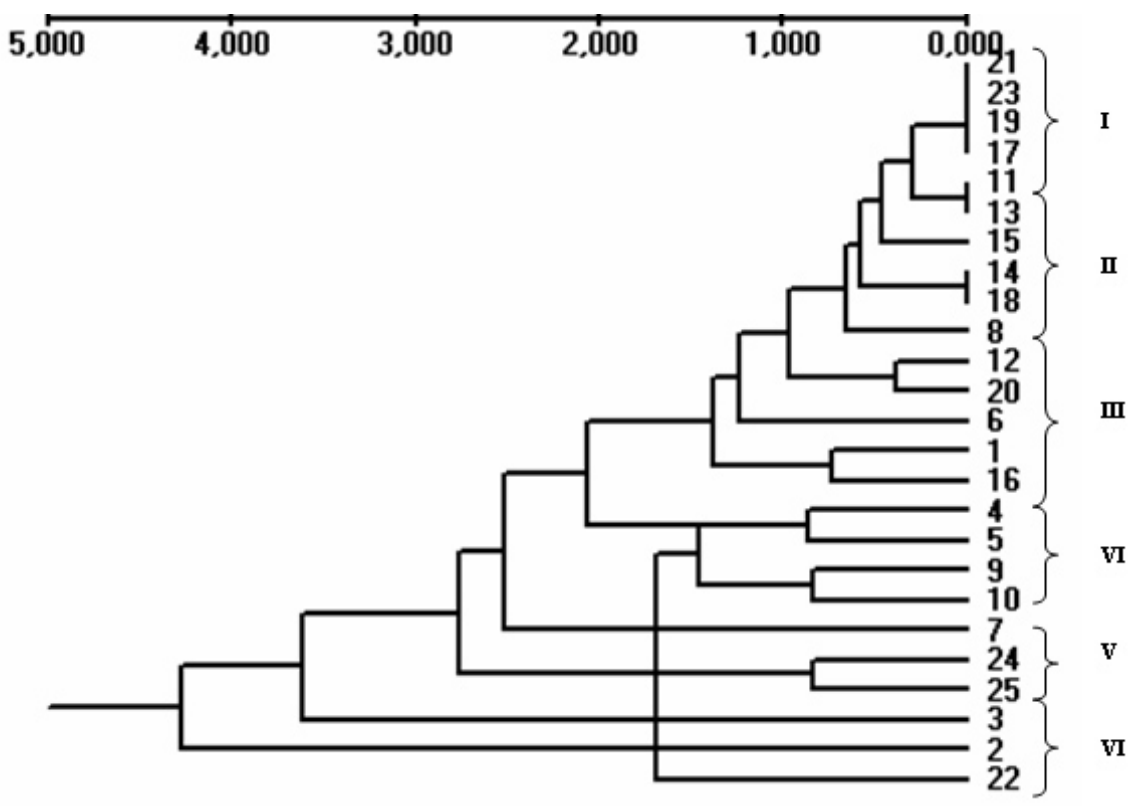

FIGURA 2 - Agrupamento construído utilizando a distância genética dos 25 genótipos de mangabeira através de marcadores moleculares RAPD, com base no coeficiente de similaridade de Nei e Li, e a distribuição dos seis grupos formados (I, II, III, IV, V e VI). 


\section{AGRADECIMENTOS}

Os autores agradecem à Fundação de Amparo à Pesquisa do Estado da Bahia, pelo apoio financeiro.

\section{CONCLUSÕES}

1- Dentre os marcadores morfoagronômicos, as variáveis massas da polpa (MP) e do fruto (MF) são as que mais contribuem para a divergência genética entre os genótipos da população avaliada.

2- Os genótipos $\mathrm{IR}_{02}$ e $\mathrm{IR}_{16}$ apresentam variabilidade genética e os maiores valores para a maioria das características físico-químicas estudadas, e podem ser usados na comercialização dos frutos e na sequência dos estudos com o melhoramento da espécie.

3- Os resultados deste estudo demonstram o potencial que a Mangaba apresenta para ser explorada tanto pelo mercado quanto por pesquisadores.

\section{REFERÊNCIAS}

BEZERRA, T.S.; COSTA, J.M.C.; AFONSO, M.R. A.; MAIA, G.A.; CLEMENTE, E. Avaliação físicoquímica e aplicação de modelos matemáticos na predição do comportamento de polpas de manga desidratadas em pó. Revista Ceres, Viçosa, MG, v.58, n 3, p.278-283, 2011.

BROWN, N.; VENKATASAMY, S.; KHITTOO, G.; BAHORUN, T.; JAWAHEER, S. Evaluation of genetic diversity between 27 banana cultivars (Musa spp.) in Mauritius using RAPD markers. African Journal Biotechnology, Victoria Island, v. 8, n.9, p.1834-1840, 2009.

CRUZ, C.D. Programa genes (versão Windows): aplicativo computacional em genética e estatística. Viçosa: UFV, 2006. p.648.

DA SILVA, A.V.C.; SANTOS, A.R.F.; WICHERT, E.; COSTA, T.S. Divergência genética entre acessos de mangabeira (Hancornia speciosa Gomes). Revista Brasileira de Ciências Agrárias, Recife, v.6, n.4, p.576-578, 2011.

DOYLE, J.J.; DOYLE, J.L. Isolation of DNA from fresh plant tissue. Focus, Gaithesburg, v.12, p.13$15,1990$.
FERREIRA, E. G.; MARINHO, S.J.O. Produção de frutos da mangabeira para consumo in natura e industrialização. Tecnologia e Ciência Agropecuária, João Pessoa, v.1, n.1, p.9-14, 2007.

GANGA, R.M.; FERREIRA, G.A.; CHAVES, L.J.; NAVES, V.R.; NASCIMENTO, J.L. Caracterização de frutos e árvores de populações naturais de Hancornia speciosa GOMES do cerrado. Revista Brasileira de Fruticultura, Jaboticabal, v.32, n.1, p.101-113, 2010.

GAUDEUL, M., TABERLET, P., BOTTRAUDTILL, I. Genetic diversity in an endangered alpine plant, Ryngium alpinum L. (Apiaceae), inferred from amplified fragment length polymorphism markers. Molecular Ecology, Foster City, v. 9. p, 1625-1637, 2000 .

GOMES FILHO, A.; OLIVEIRA, J.O.; VIANA, A.P.; SIQUEIRA, A.P.O.; OLIVIERA, M.G.; PEREIRA, M.G. Marcadores moleculares RAPD e descritores morfológicos na avaliação da diversidade genética de goiabeiras (Psidium guajava L.). Acta Scientiarum Agronomy, Maringá, v.32, n. 4, 2010.

GUASMI, F., TOUIL L.; FÉRES, K.; ELFELAH, W.; TRIKI, T.; FERCHICHI, A. Genetic diversity of Tunisian barley accessions based on microsatellites markers. Biotechnology, Nova York, v. 7, n. 4, p.781-786, 2008.

GUILHERME, D.O.; SANTOS, A.M.; PAULA, T.O.M.; ARAÚJO, C.B.; SANTOS, W.G.; ROCHA, S.L.; CALDEIRA JÚNIOR, C.F.; MARTINS, E.R. Ecogeografia e etnobotânica da mangaba (Hancornia speciosa) no norte de Minas Gerais. Revista Brasileira de Biociências, Porto Alegre, v. 5, supl. 1, p. 414-416, 2007.

INSTITUTO ADOLFO LUTZ. Métodos físicoquímicos para análise de alimentos. 4.ed. São Paulo, 2008. p.1020.

JOSHI, S.P.; GUPTA, V.S.; AGGARWAL, R.K.; RANJEKAR, P.K.; BRAR, D.S. Genetic diversity and phylogenetic relationship as revealed by inter simple sequence repeat (ISSR) polymorphism in the genus Oryza. Theoretical and Applied Genetics, Berlin, v.100, p. 1311-1320, 2000. 
MILlER, P.M. Programa TFPGA (Tools for population genetic analyses): versão 1.3. Califórnia: UCC, 1997. Disponível em: < $\underline{\text { http://bioweb.usu.edu/ }}$ mpmbio.cist.html $>$.

NEI, M.; LI, W. Mathematical model for studying genetic variation in terms of restriction endonucleases. Proceedings of the National Academy Sciences of the USA, Washington, v. 76, n.10, p. 5269-5273, 1979.

OLIVEIRA, A.C.; RICHTER, T.; BENNETZEN, J.L. Regional and racial specificities in sorghum germplasm assessed with DNA markers. Genome, Canada, v.39, p.579-587, 1996.

QIAN, W.; GE, S.; HONG, D.Y. Genetic variation within and among populations of a wild rice Oryza granulata from China detected by RAPD and ISSR markers. Theoretical and Applied Genetics, Berlin,v.102, p.440-449, 2001.

SAMAL, K.C.; JENA, R.C.; SWAIN, S.S.; DAS, B.K.; CHAND, P.K. Evaluation of genetic diversity among commercial cultivars, hybrids and local mango (Mangifera indica L.) genotypes of India using cumulative RAPD and ISSR markers. Euphytica, Netherlands, v.76, n.5, p. 1-19, 2011.
SANTOS, A.F.; SILVA, S.M.; MENDONÇA , R.M.N.; ALVES, R.E. Conservação pós-colheita de mangaba em função da maturação, atmosfera e temperatura de armazenamento. Ciência e Tecnologia de Alimentos, Campinas, v. 29, n. 1, p. 85-91, 2009.

SILVA, V.K.L.; FIGUEIREDO, R.W.; BRITO, E.S.; MAIA, G.A.; SOUSA, P.H.M.; FIGUEIREDO, E.A.T. Estabilidade da polpa do bacuri (Platonia insignis Mart.) congelada por 12 meses. Ciência e Agrotecnologia, Lavras, v.34, n. 5, p.12931300,2010

SOUZA, F.G.; FIGUEIREDO, R.W.; ALVES, R.E.; MAIA, G.A.; ARAÚJO, I.A. Qualidade pós-colheita de frutos de diferentes clones de mangabeira (Hancornia speciosa GOMES). Ciência e Agrotecnologia, Lavras, v. 31, n. 5, p. 1449-1454, 2007. 